Technological University Dublin

DÜBLIN

ARROW@TU Dublin

\title{
What do Final Year Engineering Students Know About Sustainable Development
}

lacovos Nicolaou

Technological University Dublin, d09116549@mydit.ie

Eddie Conlon

Technological University Dublin, edward.conlon@tudublin.ie

Follow this and additional works at: https://arrow.tudublin.ie/engineducart

Part of the Engineering Commons

\section{Recommended Citation}

Nicolaou, I., Conlon, E.: What do final year engineering students know about sustainable development? European Journal of Engineering Education. 2012. doi:10.1080/03043797.2012.681863

This Article is brought to you for free and open access by the Engineering: Education and Innovation at ARROW@TU Dublin. It has been accepted for inclusion in Articles by an authorized administrator of ARROW@TU Dublin. For more information, please contact arrow.admin@tudublin.ie, aisling.coyne@tudublin.ie, gerard.connolly@tudublin.ie.






\title{
What Do Final Year Engineering Students Know About Sustainable Development?
}

Iacovos NICOLAOU

\author{
School of Civil Engineering and Building Services, \\ Dublin Institute of Technology, DIT \\ and
}

Eddie CONLON,

\author{
Department of Engineering Science and General Studies, DIT, \\ Dublin, Dublin 1, Ireland
}

\begin{abstract}
This paper presents data from a project which aims to determine the level of knowledge and understanding of engineering students about Sustainable Development (SD). The data derives from a survey completed by final year engineering students in three Irish Higher Education Institutions. This paper is part of a larger study which examines the relationship between students' and teachers' understanding of SD. The results from the survey show that final year engineering students have a discipline-led conception of SD. The majority of the participants fail to acknowledge the complexity of the concept and focus only on environmental protection. Their knowledge of legislation relevant to $\mathrm{SD}$ and the social aspect of sustainability is deficient.
\end{abstract}

Keywords: Engineering Education, Sustainable Development

\section{INTRODUCTION}

This paper will focus on the knowledge and understanding of final year engineering students about Sustainable Development (SD). The data comes from a larger study, which is still in progress, which is examining the relationship between the understanding and knowledge of engineering students and their teachers about SD.

There is now a requirement that engineers practice and promote the principles of SD. The mission of Engineers Ireland (EI), the professional body for engineers in Ireland now includes a commitment to promote SD. It states: "Our members serve society through the highest standards of professional engineering. We seek to improve the quality of life for all, creating prosperity and adding value through innovation and the promotion of health, and sustainable development" (emphasis added).

It is widely accepted that engineers can play a key role in delivering sustainability [1] [2] with some arguing that they are uniquely placed to take a lead in moving towards sustainability [3]. As Johnston puts it "engineers really are necessary to make sustainability work" [4]. Moreover, Ashford argues that a specific focus should be given to engineers to achieve SD since they drive any kind of development [2].
However, existing research shows that engineering students do not understand the complexity of the concept seeing it purely as linked to environmental issues without understanding the social dimension of SD [1] [5] [6] [7] [8].

The motivation for this project was drawn from the lack of research regarding engineering education for SD in the Irish context. This is despite the requirement, set out in the Code of Professional Ethics of Engineers Ireland, for engineers to practice and promote the principles of sustainable development and the accelerating demands for engineers' competency on sustainability issues.

The work reported in this paper seeks to establish the extent to which Irish final year engineering students share the narrow view of the concept as reported in the literature. This paper seeks to build on two pieces of research that have investigated what engineering students know about SD.

\section{SD origins and definition}

Sustainable Development (SD) is a concept that was first introduced in the 1980's. The concept was presented in the World's Conservation Strategy (1980). The three main pillars that constitute SD are the environmental, the economic and the social aspect. SD is most commonly defined by the World Commission on Environment and Development, the Brundtland report [9] as "development that meets the needs of the current generation without compromising the ability of future generations to meet their own needs".

\section{What do engineering students know about SD?}

As stated above this study draws on two pieces of research which have investigated engineering students' knowledge of SD.

In the first, Carew and Mitchell [6] conducted a qualitative investigation of students' understanding of the concept in the University of Sydney. The data showed that students' understanding of SD was very broad with no evidence that they understood the complexity of the concept. They classified students' descriptions of SD. Their classification was based on an analytical framework for mapping variation in student conceptions called the Structure of Observed Learning 
Outcomes (SOLO) taxonomy introduced by Biggs and Collis [10]. The classes used for classification are in Table 1.

\begin{tabular}{|c|c|}
\hline $\begin{array}{l}\text { SOLO } \\
\text { Classes }\end{array}$ & $\begin{array}{c}\text { Features of Sustainability typical for each } \\
\text { stage }\end{array}$ \\
\hline $\begin{array}{l}\text { 1. Pre- } \\
\text { structural }\end{array}$ & $\begin{array}{l}\text { Either did not know what sustainability was or } \\
\text { provided a non-specific response }\end{array}$ \\
\hline $\begin{array}{l}\text { 2. Uni- } \\
\text { Structural }\end{array}$ & $\begin{array}{l}\text { Provided one definitive example of something } \\
\text { concrete and relevant to SD }\end{array}$ \\
\hline $\begin{array}{l}\text { 3. Multi- } \\
\text { structural }\end{array}$ & $\begin{array}{l}\text { Provided two or more different examples of } \\
\text { things relevant to SD }\end{array}$ \\
\hline 4. Relational & $\begin{array}{l}\text { Constructed a cohesive statement about SD by } \\
\text { relating two or more things relevant to SD }\end{array}$ \\
\hline $\begin{array}{l}\text { 5. Extended } \\
\text { Abstracts }\end{array}$ & $\begin{array}{l}\text { Constructed a cohesive statement about SD by } \\
\text { relating two or more things relevant to SD and } \\
\text { provided evidence of critical/creative thinking } \\
\text { or ethical judgment }\end{array}$ \\
\hline
\end{tabular}

Table 1: Carew's and Mitchell SOLO taxonomy [6]

The results of the classification showed that $65 \%$ of the responses were classified as pre-structural and uni-structural which corresponds to answers that either did not know what sustainability is; or had a very vague perception of the concept. $18 \%$ of the responses were classified as multi-structural which corresponded to answers where an attempt to define sustainability was based on the combination of two relevant aspects of the concept such as environmental protection and future needs. The remaining $17 \%$ was allocated to relational and extended abstract classes which included responses showing knowledge evidence of critical thinking and ethical responsibility. Carew and Mitchell argued that the results are concerning since the respondents were at the third year of their degree which assumes that some modules relevant to SD were completed by them. They said that curricula should be improved in order to facilitate students that have a pre-structural conception and assist them to develop their knowledge, while the same system would provide opportunities to more knowledgeable students to further explore the concept.

In the second investigation, Azapagic and her co-researchers [1] carried out an international quantitative survey of engineering students in order to determine their level of knowledge and understanding of SD and identify knowledge gaps. The survey was distributed to 21 countries and a total of 3134 students completed the questionnaire. The data showed that engineering students tend to connect SD with environmental issues and neglect the other two pillars of the concept (economic and social). The results show that students' knowledge and understanding of SD was particularly low. Substantial knowledge gaps were found in regard to SD legislation, policy and standards, SD social issues and several environmental issues such as loss of biodiversity and salinity.

Azapagic also found that respondents thought that SD is an important concept for them; and more important for future generations. Their results did not show any significant difference when variables such as gender, discipline and year of study were examined. Nevertheless, participants from Sweden, Vietnam and Germany were distinguished from the sample with a higher level of knowledge of SD compared with other participating countries such as UK, Central Europe and the U.S.A. Based on the above, Azapagic [1] argues that engineering students' level of knowledge and understanding of SD is "not satisfactory" and that deficiencies in engineering education should be minimized in order to adequately educate engineering students and close the knowledge gaps mentioned above.

Carew's and Mitchell [6] and Azapagic's et al [1] work showed major gaps in engineering students' knowledge and understanding of SD.

This study draws from those two projects as a framework to determine the level of knowledge and understanding of final year engineering students of SD in the Irish context. The results will be presented in the results section where comparisons will be made between our results and those from Azapagic et al [1] and Carew and Mitchell [6].

\section{METHODOLOGY}

The data reported in this paper comes from a survey of final year engineering students across a range of engineering disciplines in a number of Irish higher education institutions (Table 1). One of the institutions is ranked as one of the top 56 higher education institutions that promote SD in engineering education [11]. The institutions are located in three different cities. One of them is a traditional and long standing university; one is a new university having achieved university status in 1989; while the third is an institute of technology offering programs from traditional apprenticeships to doctorates.

\begin{tabular}{|c|c|c|c|c|c|}
\hline Degree & $\begin{array}{c}\text { Civil } \\
\text { Eng }\end{array}$ & $\begin{array}{c}\text { Mechanical } \\
\text { Eng }\end{array}$ & $\begin{array}{c}\text { Chemical } \\
\text { Eng }\end{array}$ & $\begin{array}{c}\text { Structural } \\
\text { Eng }\end{array}$ & $\begin{array}{c}\text { Building } \\
\text { Services }\end{array}$ \\
\hline Inst. 1 & $\times(25)$ & $\times(29)$ & & $\times(26)$ & $\times(25)$ \\
\hline Inst. 2 & $\times(23)$ & & $\times(7)$ & & \\
\hline Inst. 3 & & $\times(8)$ & & & \\
\hline
\end{tabular}

Table 2: The three Institutes and the degrees surveyed. Numbers in parentheses illustrate response from each degree and institute.

A questionnaire was designed drawing on that used by Azapagic et al. [1]. Carew's and Mitchell [6] open-ended approach was incorporated asking students to state, in their own words, their understanding of SD. However, the two questionnaires were not identical. Additions were made in order for the questionnaire to be appropriate for the Irish context. SD principles were drawn from Ireland's SD Council, Comhar [12] while SD tools were identified in Mulder's book on SD for engineers [13].

The main research question "What is the level of knowledge and understanding of fourth year engineering students of SD" was utilized to generate subsequent questions that were used in the survey. The questionnaire consisted of four sections as follows:

- Section 1: Demographic and institutional data Gender, age, Institution and Degree, Transfer from a Level 7 Degree. 
- $\quad$ Section 2: Open Ended Question - participants were asked to state in their own words their understanding of SD.

- Section 3: Scaled Questions - this section was designed based on Azapagic et al [1]. Students were asked to rate their knowledge about SD principles, legislation, issues, SD tools and organizations that promote SD. The scale used was: 1: Never Heard of, 2: Heard but could not explain, 3: Have some Knowledge, 4: Know a lot.

- Section 4: students were asked to rate the importance of SD at a personal and professional level.

The questionnaire was distributed both online and on paper in order to enhance the response rate and improve the results. In total, 143 fourth engineering students completed the questionnaire with a response rate of $54 \%$ across all disciplines. These included 48 Civil, 37 Mechanical, 26 Structural, 25 Building Services and 7 Chemical Engineers. It can be seen from Table 2 that most respondents came from one institution. The response from Institution 3 was very low making it difficult to make comparisons across institutions.

The data were analysed with SPSS 18 . Raw data from the scaled sections were analysed in regard to frequency, average and also cross-tabulated with the key variables to test the significance of their impact. Open-ended responses were coded based on the three pillars of SD (Table 3).

Within Table 3 each class corresponds to specific key words related with each pillar that occurred in responses. Class 1 corresponded to answers that mentioned all three pillars of SD. Classes 2-7 show all the possible combinations of the pillars that might occur in other responses. Class 8 corresponds to answers that quoted Brundtland's definition. Class 9 was created for answers that showed no knowledge of SD.

Class 1 could be identified as a Relational class based on Carew's and Mitchell [6] taxonomy. Classes 2, 3 and 4 as Multi-structural; 5, 6, 7 and 8 as Uni-structural and 9 as prestructural.

\begin{tabular}{|c|c|}
\hline Classes & $\begin{array}{c}\text { Key words } \\
\text { Economy: long term } \\
\text { Society } \\
\text { planning, cost-payback } \\
\text { analysis, development, } \\
\text { growth, save money, } \\
\text { economic }\end{array}$ \\
2. Economy-Environment & $\begin{array}{c}\text { Environment: } \\
\text { environmental protection, } \\
\text { limitations, eco friendly, } \\
\text { impact, footprint, waste } \\
\text { minimization, non and } \\
\text { renewable resources } \\
\text { 3. Economy-Society } \\
\text { 4. Environment-Society } \\
\text { 5. Economy }\end{array}$ \\
\cline { 1 - 1 } 6.Environment & social balance, equity. \\
\hline 7.Society & \\
\hline 9. No evidence of knowledge & \\
\hline
\end{tabular}

Table 3: Classes used for coding open-ended responses.
The results are presented and discussed in the following section.

\section{RESULTS}

Aggregated results for all topics in the questionnaire indicated that engineering students' knowledge of SD is between "Heard but could not explain" and "Have some knowledge" with a corresponding overall average of 2.49. Although the overall average of this study is higher than Azapagic's 2.23 [1], further comparison showed that both studies illustrate the same overall pattern in engineering students' knowledge and understanding. When comparisons were drawn on topics common to both studies, it was found that averages for three sections fell closer to those found by Azapagic et al [1]. In one case, SD principles, the average fell below the average found in Azapagic's study (Figure 1).

The data shows that fourth year engineering students from the three Irish Higher Education institutions seem to be more knowledgeable in regard to sustainability issues with an average score of 2.86. Substantial knowledge gaps were identified in regard to SD principles and SD legislation, policy and standards. Figure 1 represents the average scores of this study and Azapagic's comparable average scores.

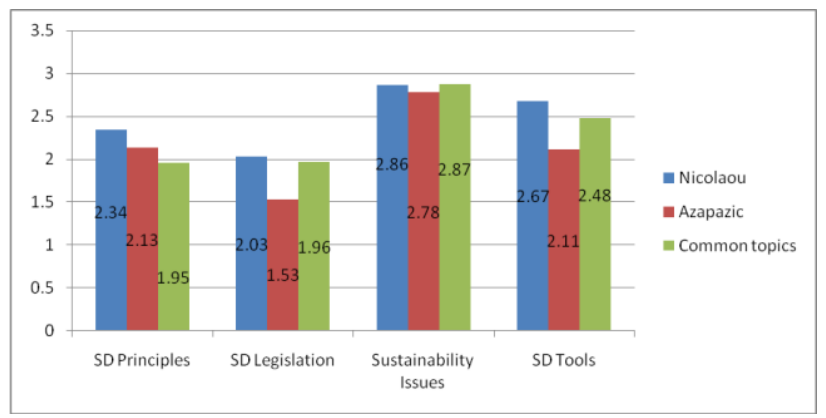

Figure 1: Section averages compared with Azapagic et al [1].

The scores show an inadequate level of knowledge and understanding of fourth year engineering students of SD in the Irish context.

\section{SD principles}

In relation to SD principles question, the overall average of 2.34 is just above "Heard but could not explain". Students rated their knowledge high in regard to the topics of "Engineering Ethics" with an average of 3.12 and "Minimizing the utilization of nonrenewable resources" with an average of 3.09. Yet, considerable knowledge gaps were identified with principles regarding social issues. The latter seems to contradict with the high average score for "Engineering Ethics".

Student's ratings in regard to topics "Inter-generational equity", "Intra-generational equity" and "Social Inclusion" were below 2 which is just above "Never Heard of". More specific, "Intergenerational equity" had an average score of 1.48, "Intragenerational equity" 1.47 and "Social Inclusion" an average score of 1.88. Despite the higher overall average of this section, Inter and Intra generational had a lower average score than Azapagic's score (1.67). Moreover several other topics had a low score such as "Stakeholder Participation" (1.9) compared to Azapagic's (1.67); "Principle of Subsidiarity" (1.65) and the "Precautionary Principle" with an average of 1.58. 


\section{SD legislation, policy and standards}

Turning to consider SD legislation, policy and standards it was found that three topics had a considerably higher average score than the section's overall average (2.03): "Kyoto Protocol" (2.94); "Ireland's Renewable Energy Targets" (3.01) and "Environmental Impact Assessment (EIA)" (2.92). Following the very low averages on social issues in the SD principles question, students' knowledge about legislation regarding social inclusion was significantly low. The topic "Aarhus Convention" had an average score of 1.19. Moreover, topics such as "Rio Declaration" and "Agenda 21" had low average scores of 1.42 and 1.43 respectively.

\section{SD issues}

The literature clearly states that engineering students tend to connect SD with environmental issues [1] [5] [6] [7] [8] [9]. Our data presents further evidence to support this view.

As previously stated, SD issues had the highest overall average score in this survey with a score of 2.86. Students gave a very high score to a number of environmental issues including "Climate Change" (3.49). Other topics in this section received an average score close to 3 . However, relatively low scores were recorded for the topics "Ecosystems" at 2.47 and "Loss of Biodiversity" at 2.26. The topic "Loss of Biodiversity" was scored as the lowest also in Azapagic's study (2.21).

\section{SD tools}

In regard to SD tools section, students' responses showed an overall average score of 2.67 , which was significantly higher than Azapagic's respondents (2.11). A higher score was given to the topic of "Recycling" (3.30). Average scores of 3.16 and 3.22 were recorded for the topics of "Renewable Energy Technologies" and "Use of renewable materials" respectively. Substantially lower than the overall average was the topic of "Tradable Permits" with an average score of 1.69 which it was also low in Azapagic's work with an average score of 1.82.

\section{Organizations that promote SD}

Students were also asked to rate their knowledge about several engineering bodies and international organizations that promote SD. The overall average of this section was 2.57 which lies between the statements of "Heard but could not explain" and "Have some knowledge". In this section, students had a good knowledge about "Engineers Ireland" with an average score of 3.39 and also about "Sustainable Energy Authority Ireland (SEAI)".

On the other hand a low average score of 1.73 was allocated to "Comhar, Sustainable Development Council" which is the National Development Council for Ireland. Comhar has published SD principles which Engineers Irelands have subscribed to.

A low average score of 1.97 was given to the "Intergovernmental Panel on Climate Change (IPCC)" topic.

\section{Importance of SD}

In Section 4, engineering students were asked to rate the importance of SD at the personal and professional level.
$43.1 \%$ of the students rated SD as "Important" at a personal level, while $44.8 \%$ rated SD at a personal level as "Very Important". This corresponds to an average of 3.32 in a scale of 1-4. Azapagic et al [1] used the same scale to analyze this particular question which showed an average of 3 .

On the other hand students' rating of the importance of SD at a professional level was higher that the personal level; 98.3\% said that SD is either "Important" or "Very Important". More specifically, $72.4 \%$ rated SD as "Very Important" and $25.9 \%$ as "Important" at a professional level. This average 3.7 was higher, than Azapagic's average score of 3.3.

\section{Key variables significance tests}

Significance tests were performed using the Pearson Chi-square significance test in SPSS 18. Any chi-square smaller than 0.05 $(<0.05)$ shows a significant impact of the testing key variable on the data. Age was the only key variable that had no impact on the survey data. On the other hand, on the aggregated 65 topics included in all sections, institution had a significant impact on 9 of them corresponding to $14 \%$. This is not surprising given that the majority of respondents came from one institution.

Azapagic and her co-researchers [1] found that their results were not affected at all by key variables that had a connection with the participants' studies including their discipline.

However, chi-square tests in this study showed that degree was the primary variable impacting the results. Cross-tabulation of the degrees with the topics and chi-square performance showed that degree had a significant impact on the students' knowledge of 39 of 65 topics in the questionnaire, amounting to $60 \%$ of the topics surveyed. This suggests that engineering students' knowledge of SD is discipline-led.

Knowledge of nine of eighteen topics $(50 \%)$ included in SD principles section; twelve of fourteen topics (85.7\%) included in SD legislation section; seven of fifteen topics (46.7\%) in SD tools; eight of twelve topics (66.7\%) in SD issues and three of six topics $(50 \%)$ in the organizations section were affected by the students' disciplines.

What seems to emerge from this analysis is that some disciplines are addressing discipline specific issues relatively well. What also emerges is that some issues such as Climate Change, Recycling and Deforestation score high independently of the discipline.

Another set of issues which include key social issues such as social equity and inclusion but also important legislation such as the Aarhus Convention score low regardless of discipline.

It is also worth noting that knowledge of the "Precautionary Principle" is scored low across all disciplines.

\section{SD definition}

Open-ended responses were coded based on the classification presented in Table 4. Figure 2 shows the results of the analysis. Based on the classification, engineering students define SD as a concept that is connected mainly with economic and environmental issues while failing to acknowledge the equal importance of the social aspect in SD. 


\begin{tabular}{|l|c|}
\hline Classes & 1. Economy-Environment-Society \\
\hline \multirow{4}{*}{} & 2. Economy-Environment \\
\cline { 2 - 3 } & 3. Economy-Society \\
\cline { 2 - 3 } & 4. Environment-Society \\
\cline { 2 - 3 } & 5. Economy \\
\cline { 2 - 3 } & 6.Environment \\
\hline & 7. Brundtland Definition \\
\cline { 2 - 3 } & 9. No evidence of knowledge \\
\hline
\end{tabular}

Table 4: Classes utilized for open-ended responses classification

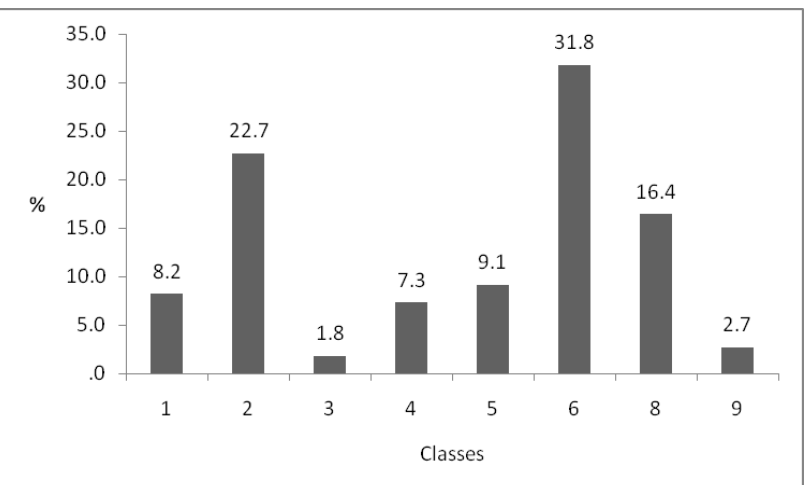

Figure 2: Classification of open-ended responses

Responses that define SD as a concept that consist of the three pillars, the economy, the environment and the society are classified as Class 1 which corresponds to a very low percentage of $8.2 \%$.

A large group of participants $(31.8 \%)$ described SD as strictly an environmental concept. In an attempt to aggregate all the classes that involve the environmental pillar, excluding Class 1, a large percentage of participants $(61.8 \%)$ included the environment in their description of SD.

On the other hand, an aggregated percentage of the societal pillar is low at $9.1 \%$, with Class 7 not having any responses.

Interestingly Brundtland's definition corresponds to $16.4 \%$ of the responses which supports the fact that is a commonly used definition of SD.

All of the above show that fourth year engineering students have a very narrow understanding of SD which supports the findings from the scaled questions where results showed that students know very little about social issues.

An initial classification of these responses based on Carew's and Mitchell [6] taxonomy, showed that responses from this study are primarily uni-structural (Figure 3 ). Class 8 responses were classified as uni-structural in line with the approach taken by Carew's and Mitchell.

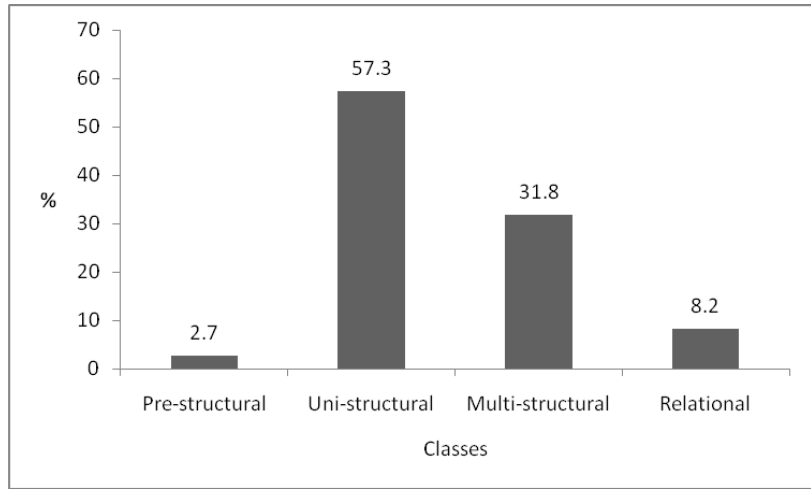

Figure 3: Classification of open-ended responses based on Carew and Mitchell's analytical framework

Classification of responses from this study, based on the SOLO taxonomy, follows a similar pattern as those from Carew's and Mitchell study. The majority were classified as uni-structural: Carew and Mitchel was 55.8\% while ours was $57.3 \%$.

While the proportion of Relational responses was lower in our study $(8.2 \%$ as against $13.5 \%)$, there was a smaller proportion of Pre-structural answers (2.7\% as against $9.6 \%)$. Both studies show that most students have a uni or multi-structural understanding of SD.

Figure 3 supports the argument rising from this study that students' understanding of the complexity of SD is very low. Students fail to acknowledge the inter-connectedness of the three pillars and tend to relate SD only with environmental issues.

\section{CONCLUSIONS}

The survey conducted for the purposes of this study showed that engineering students' knowledge in regard to SD topics is inadequate. It is concerning that respondents were fourth year engineering students who are just about to graduate.

The results follow the same pattern and identify the same knowledge gaps in engineering students' knowledge of SD as identified in Azapagic's et al study.

Substantial knowledge gaps are identified in regard to SD social issues, and SD legislation, policy and standards. Key SD issues such as "Loss of Biodiversity" and "Ecosystems" had a score significantly lower than the overall average which shows that engineering students also have significant knowledge gaps in environmental assessment and protection.

Several topics with a significantly high score such as "Recycling", "Climate Change" and the "Kyoto Protocol" have a high public profile. It is the case that these issues have achieved media coverage and are much discussed in political and public forums. It might be the case that students' knowledge is significantly impacted by the media coverage of these issues.

It is interesting to note that while students seem to know a lot about Climate Change, they have a poor knowledge of topics such as "Intergovernmental Panel on Climate Change (IPCC)" and "Tradable Permits". These topics relate more to the economic and political domain rather than to engineering. 
Engineering students see the implementation of SD to be more of a professional requirement rather than an issue of personal commitment. They are more likely to say that it is very important for them as professionals. This suggests that the curriculum may not be generating a personal commitment to sustainability among engineering students and they might see sustainability as yet another constraint that engineers must grapple with in their engineering practice.

Fourth year engineering students' level of understanding of the complexity of SD is low. They directly connect SD with environmental issues while they neglect the social aspect of SD. They tend to define SD by referring to only one of the three pillars. Very few demonstrate Relational understanding of the concept while none had an Extended Abstract conception. It is the case thought that very small numbers have no knowledge at all.

This study has also showed engineering students' level of knowledge and understanding to be discipline-led.

SD is a multi-disciplinary concept that requires the involvement of the engineering sector. However, if engineers' competence is low as this study has shown, sustainability issues will not be effectively assessed by engineers. As Beder [14] has argued, "engineers of the future are professionals that understand SD and provide solutions that are appropriate in the three aspects of SD".

The present study generates new research questions such as the reasons why students have a narrow understanding of SD. The next stage in this project will seek to build on the data reported here.

We will be surveying first year engineering students with the same questionnaire. This will allow us to determine the degree to which pre-engineering experiences are affecting students' knowledge of SD.

We will also explore staff's understanding of SD. It might be the case that while academics might believe they are giving adequate coverage to SD issues these might be too discipline (and technology) specific. The result might be that students are not getting the general and broad education that they need to fully understand SD.

\section{REFERENCES}

[1] A. Azapagic, S. Perdan, D. Shallcross, How much do engineering students know about sustainable development? The findings of an international survey and possible implications for the engineering curriculum, European Journal of Engineering Education, Vol. 30, No. 1, 2005, pp 1-19

[2] N. Ashford, Major challenges to engineering education for sustainable development, International Journal of Sustainability in Higher Education, Vol. 5, No. 3, 2004, pp 239-250

[3] S Johnston, H. McGregor, E. Taylor, Practice-focused ethics in Australian engineering education, European Journal of Engineering Education, Vol. 25, No. 4, 2000, pp 315-324
[4] S. Johnston, Sustainability, Engineering and Australian Academe, Society for Philosophy and Technology Quarterly Electronic Journal, Vol. 2, No. 3/4. 1997, p 92

[5] J.R. Herkert, Sustainable development, engineering and multinational corporations, Science and Engineering Ethics, Vol. 4, No. 3, 1998, pp 333-346

[6] A.L. Carew, C.A. Mitchell, Characterizing undergraduate engineering students' understanding of sustainability, European Journal of Engineering Education, Vol. 27, No. 4, 2002, pp 349-361

[7] J. Segalas, D. Ferrer-Balas, K.F. Mulder, Conceptual maps: measuring learning processes of engineering students concerning sustainable development, European Journal of Engineering Education, Vol. 33, No. 3, 2008, pp 297-306

[8] F. Kagawa, Dissonance in students' perceptions of sustainable development and sustainability - Implications for curriculum change, International Journal of Sustainability in Higher Education, Vol. 8, No. 3, 2007, pp 317-338

[9] World Commission on Environment and Development (WCED), Our Common Future. Oxford University Press. 1987

[10] J.B. Biggs, K.F. Collis, Evaluating the Quality of Learning: The SOLO Taxonomy, New York: Academic Press, 1982

[11] Engineering Education for Sustainable Development Observatory (EESD), Report 2008, Available at https://www.upc.edu/eesdobservatory/why/reports/EESD_Observer_2008_.pdf/view

[12] Comhar, Sustainable Development Council, Principles for Sustainable Development, 1997, Available at http://www.comharsdc.ie/ files/S.D.Principles.pdf

[13] K. Mulder, Sustainable Development for Engineers, 2006, Greenleaf Publishing, UK

[14] S. Beder, Toward an environmentally conscious engineering graduate, Australasian Journal of Engineering Education, Vol. 7, No. 1, 1996, pp 39-45 